\title{
Prevalence and risk factors associated with self-reported carpal tunnel syndrome (CTS) among office workers in Kuwait
}

\author{
Sudha R Raman ${ }^{1,2}$, Becher Al-Halabi', Elham Hamdan ${ }^{1}$ and Michel D Landry ${ }^{1,2,3^{*}}$
}

\begin{abstract}
Background: The prevalence of carpal tunnel syndrome (CTS) is not well understood in many Arabian Peninsula countries. The objective of this study was to investigate the prevalence and factors associated with self-reported CTS in Kuwait.

Findings: A cross-sectional, self-administered survey of CTS-related symptoms was used in this study. Multivariate logistic regression was also used to estimate adjusted odds ratios for factors of interest. Participants in this study were adult office workers in Kuwait ( $n=470,55.6 \%$ males), who worked in companies employing more than 50 people. Self-reported CTS was reported in $18.7 \%$ of the group (88/470). CTS was significantly associated with the following demographic factors: female gender, obesity and number of comorbid conditions. Self-identification of CTS was also associated with key symptoms and impairment in daily activities (e.g., wrist pain, numbness, weakness, night pain, difficulty carrying bags, difficulty grasping [Chi-Square Test for Association: $P<0.05$ for all symptoms/ activities]). However, symptoms such as wrist pain, weakness, and functional disabilities were also frequently reported among those who do not self report CTS (range: 12.1\%-38.2\%).

Conclusions: Prevalence of self-reported CTS among office workers in Kuwait is 18.7\%, and the risk factors for CTS in this population included female gender, obesity and number of related comorbidities. The frequency of symptoms in the sample who did not self report CTS suggest that CTS may be under-recognized, however further research is required to assess the prevalence of clinically diagnosed CTS.
\end{abstract}

Keywords: Carpal tunnel syndrome, Prevalence, Occupational exposure, Kuwait

\section{Background}

Carpal tunnel syndrome (CTS) is a common musculoskeletal condition, and while diagnostic criteria for CTS can vary, the clinical profile typically includes a combination of clinical assessment of symptoms (e.g., numbness, tingling, night pain and paraesthesia), signs (e.g.,Tinel's sign, Phalen's sign) and/or nerve conduction velocity (NCV) testing of the median nerve across the carpal tunnel [1,2]. Prevalence estimates of CTS in the general adult population range from approximately $1 \%$ to $16 \%$ [3-6]. Little is known about the prevalence, costs and potential contributing factors of CTS in the Arabian

\footnotetext{
* Correspondence: mike.landry@duke.edu

'Fawzia Sultan Rehabilitation Institute, Kuwait

${ }^{2}$ Doctor of Physical Therapy Division, Dept of Community and Family

Medicine, Duke University, Box 104002, Durham NC 27708, USA

Full list of author information is available at the end of the article
}

Peninsula region, including Kuwait [7]. In Kuwait, high levels of overweight and obesity, diabetes mellitus, and cigarette smoking [8,9], and other known risk factors for CTS $[10,11]$ may suggest that CTS is an emerging workplace and occupational health issue. The purpose of this study was to estimate the prevalence of self-reported CTS among office workers in Kuwait, and to identify risk factors associated with CTS in this population.

\section{Findings}

\section{Methods \\ Participants}

A convenience sample of companies in Kuwait City employing 50 or more people were approached by the research team between June and July 2008 about participation in the study. All companies who were approached

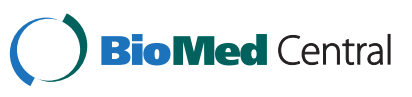


agreed to collaborate by allowing their individual employees to voluntarily participate in a questionnaire regarding CTS. In order to be included in this study, individual participants were required to be 20 years old or older, have an office job where their work duties and tasks were primarily related to administrative, computer and/or desk work, and be willing to complete the survey in English. In each location or participating company, a list of all employed office workers who met the inclusion criteria was obtained by the appropriate human resource department. Trained data collectors then described the study purpose and objectives to all potential participants, and at that time it was clarified that choosing to participate represented informed consent to participate in this study. Questionnaires were then distributed to all employees who agreed to participate. Ethics approval for this study was obtained through the Fawzia Sultan Rehabilitation Institute.

\section{Survey tool development}

The data collection tool used in this study was a selfadministered questionnaire that required approximately 15 minutes to complete. The questionnaire was developed specifically for the purpose of this study, and was pilot tested with 10 office workers employed by companies outside the study sample. Feedback from pilot testing resulted in clarification of the wording of 20 of 61 questions; and in all cases, changes were incorporated into the final questionnaire.

\section{Study measures and variables}

There were three sets of questions in the survey (Additional file 1). The first set of questions was related to participant characteristics such as gender, age, height, weight, and nature of occupation (i.e. type of job). Body mass index (BMI: weight $(\mathrm{kg}) /$ height $\left.(\mathrm{m})^{2}\right)$ was calculated and categorized according to World Health Organization (WHO) guidelines [12]. The second set of questions was related to CTS status. After reading a definition of CTS, participants who indicated 'yes' to the question, "Do you think you have Carpal Tunnel Syndrome?" were considered to have self-reported CTS. Participants self-reporting CTS were asked to indicate the duration, frequency, and severity of symptoms, the effect of their symptoms on work and daily activities disability, the effect of work on their development of CTS and whether they had been diagnosed with CTS by a health professional. The third set of questions was designed to test for the presence of CTS symptoms and risk factors via a series of questions for all participants regarding wrist pain, numbness, weakness, motor function, history of trauma, computer use and whether they suffered from any of 12 co-morbidities identified a priori from the literature [13-16]. Participants were also asked to indicate
Table 1 Sociodemographic and health characteristics of 470 office workers from 12 different companies in Kuwait City collected in June/July 2008

\begin{tabular}{lrr}
\hline \multicolumn{1}{c}{ Characteristics } & Total for Item & N (\%) \\
\hline Gender & 466 & \\
Male & & $259(55.6)$ \\
Female & & $207(44.4)$ \\
Age group (years) & 466 & \\
$20-30$ & & $283(60.7)$ \\
$31-40$ & & $111(23.8)$ \\
$41-50$ & & $55(11.8)$ \\
$51+$ & & $17(3.7)$
\end{tabular}

Marital status $\quad 467$

Married

$239(51.2)$

Single

$210(45.0)$

$18(3.9)$

Divorced/widowed

$444(98.2)$

$8(1.8)$

Labor

452

Work type

$8(1.9)$

Body mass index (BMI)

432

Underweight (BMI: < 18.5)

$162(37.5)$

Normal (BMI: $18.5-<25)$

$172(39.8)$

$90(20.8)$

Obese (BMI: 30+)

413

Self-rated health

$174(42.1)$

Excellent/very good

164 (39.7)

Good

$75(18.2)$

Previous wrist injury

413

Yes

$84(20.3)$

No

Computer Use

$8(2.0)$

None

$115(29.0)$

$<3$ hours per day

$274(69.0)$

$>3$ hours per day

381

Number of comorbidities

$247(64.8)$

75 (19.7)

$35(9.2)$

$24(6.3)$

$3+$

369

\begin{tabular}{lr}
0 hour/week & $134(37.7)$ \\
1 hour/week & $114(30.9)$ \\
$\geq 2$ hours/week & $116(31.4)$ \\
Smoking status & 362 \\
Yes & \\
No & $96(26.5)$ \\
\hline
\end{tabular}


their smoking status, exercise frequency and perception of their general health.

\section{Data entry and analysis}

Data were entered into a data file located on a passwordprotected computer in the research offices of Fawzia Sultan Rehabilitation Institute. Statistical analyses were conducted using SAS (SAS Institute Inc, Cary, North Carolina). Proportions were calculated to describe the outcome of interest (prevalence of self-reported CTS), demographic characteristics and CTS symptoms and disability. Symptom prevalence in individuals reporting CTS was compared to individuals not reporting CTS using Chi-square tests of association. The primary outcome variable of interest was self-reported CTS. Odds ratios and $95 \%$ confidence intervals (95\% CIs) comparing individuals who reported CTS and individuals who did not, were calculated for factors of clinical interest (gender, age, BMI, self-rated health, previous wrist injury, computer use, number of co-morbid conditions, exercise frequency and smoking status). A best-fit logistic regression model of predictor variables for self-reported CTS was found using backward selection, starting from the full set of nine variables listed above. Adjusted odds ratios and 95\% CIs for the variables remaining in the best-fit model were also calculated.

\section{Results}

A total of 470 office workers from 12 different companies in Kuwait City participated in this study. Of those reporting, $55.6 \%$ were male, $60.7 \%$ were aged $20-30$ years of age, and $60.6 \%$ were overweight or obese (Table 1 ).

\section{Self-reported CTS}

CTS was self-reported by $18.7 \%$ of the group (88/470). Of these individuals, over $30 \%$ reported that they experience the typical symptoms 'daily' or 'always' (Figure 1). Length of time since first noticing symptoms was less than one year for $37.5 \%$ of the sample, between 1 and 5 years for $43.2 \%$ of the sample, and longer than 5 years for almost $7 \%$ of the sample $(12.5 \%$ did not indicate symptom duration). Only fifteen respondents indicated that they had taken sick leave because of their CTS. Of those self-reporting CTS, 71.6\% (63/88) indicated that they believed their CTS was related to their work duties. Thirteen (14.8\%) of those self-reporting CTS (or $2.8 \%$ of the entire sample) indicated that they had been previously diagnosed with CTS by a healthcare professional.

In bivariate analysis, self-reported CTS was significantly more likely to be found in females than in males, in individuals aged 31-40 years than in those aged 2030 years, in obese individuals $(\mathrm{BMI}>30)$, in those with a previous wrist injury, in those who rarely or never exercise, and in those who reported relevant comorbidities (Table 2). Due to small sample sizes for many of the investigated comorbidities, we focused on number of these comorbidities, rather than on the specific conditions. However, exploratory testing of the four most common conditions amongst the study population showed that CTS was more likely to be self-reported by individuals with depression (odds ratio, 95\% CI: 3.1, 1.6$6.2)$, previous trauma to the cervical spine $(4.2,2.1-8.5)$, arthritis $(2.5,1.9-5.3)$ or diabetes $(3.6,1.5-7.6)$ than individuals without these individual conditions.

The best-fit logistic regression with multiple predictors of self-reported CTS included a subset of the

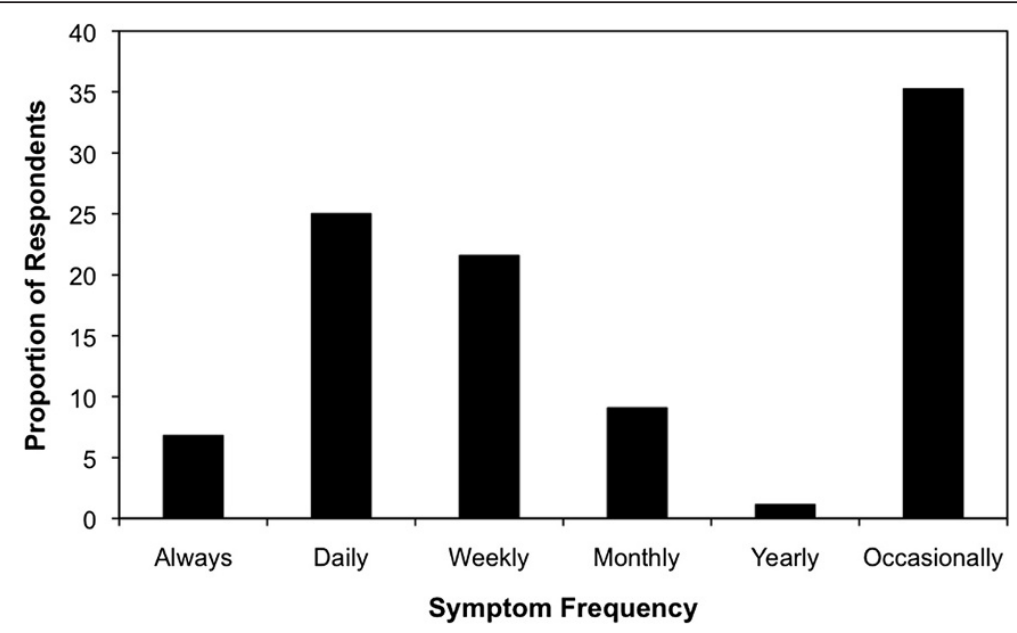

Figure 1 Frequency of reported CTS symptoms amongst those who self-report CTS $(\mathbf{n}=\mathbf{8 8})$. Detailed Legend: Note that one individual did not indicate symptom frequency. 
Table 2 Prevalence and odds ratios (OR) of self-reported CTS by sociodemographic and health factors of interest among office workers (Kuwait City, 2008)

\begin{tabular}{|c|c|c|c|c|c|c|}
\hline & Total respondents & $\%$ (n) with CTS & OR & $95 \% \mathrm{Cl}$ for OR & Adjusted $\mathrm{OR}^{*}$ & 95\% $\mathrm{Cl}$ for Adjusted $\mathrm{OR}^{*}$ \\
\hline Gender & 456 & & & & & \\
\hline Male & 254 & $13.4(34)$ & 1.0 & Reference & 1.0 & Reference \\
\hline Female & 202 & $25.3(51)$ & 2.2 & $1.4,3.5$ & 4.7 & $2.1,10.3$ \\
\hline Age group (years) & 456 & & & & & \\
\hline $20-30$ & 276 & $16.7(46)$ & 1.0 & Reference & & \\
\hline $31-40$ & 109 & $27.5(30)$ & 1.9 & $1.1,3.2$ & & \\
\hline $41-50$ & 54 & $16.7(9)$ & 1.0 & $0.5,2.2$ & & \\
\hline $51+$ & 17 & $17.7(3)$ & 1.1 & $0.3,3.9$ & & \\
\hline Body mass index & 422 & & & & & \\
\hline Underweight & 8 & $0.0(0)$ & NE & $\mathrm{NE}$ & omitted & omitted \\
\hline Normal & 160 & $16.2(26)$ & 1.0 & Reference & 1.0 & Reference \\
\hline Overweight & 167 & $15.6(26)$ & 1.0 & $0.5,1.7$ & 0.8 & $0.3,1.9$ \\
\hline Obese & 87 & $29.9(26)$ & 2.2 & $1.2,4.1$ & 3.7 & $1.5,9.6$ \\
\hline Self-rated health & 404 & & & & & \\
\hline Excellent/very good & 170 & $10.0(17)$ & 0.4 & $0.2,3.3$ & & \\
\hline Good & 160 & $23.1(37)$ & 1.0 & Reference & & \\
\hline Fair/poor & 74 & $35.1(26)$ & 1.8 & $1.0,3.3$ & & \\
\hline Previous wrist injury & 405 & & & & & \\
\hline Yes & 82 & $29.3(24)$ & 1.9 & $1.1,3.3$ & & \\
\hline No & 323 & $18.0(58)$ & 1.0 & Reference & & \\
\hline Computer use & 389 & & & & & \\
\hline None & 8 & $0.0(0)$ & NE & $\mathrm{NE}$ & & \\
\hline$<3$ hours per day & 111 & $14.4(16)$ & 1.0 & Reference & & \\
\hline$>3$ hours per day & 270 & $21.1(57)$ & 1.7 & $0.9,3.1$ & & \\
\hline Number of comorbidities & 373 & & & & & \\
\hline 0 & 244 & $10.2(25)$ & 1.0 & Reference & 1.0 & Reference \\
\hline 1 & 70 & $28.6(20)$ & 3.5 & $1.8,6.8$ & 4.9 & $2.0,12.3$ \\
\hline 2 & 35 & $31.4(11)$ & 4.0 & $1.8,9.2$ & 3.3 & $1.1,9.7$ \\
\hline $3+$ & 24 & $62.5(15)$ & 14.6 & $5.8,36.8$ & 14.9 & $4.8,46.5$ \\
\hline Exercise frequency & 361 & & & & & \\
\hline 0 hours/week & 137 & $24.8(34)$ & 1.0 & Reference & & \\
\hline 1 hour/week & 112 & $21.4(24)$ & 0.8 & $0.5,1.5$ & & \\
\hline$\geq 2$ hours/week & 112 & $9.8(11)$ & 0.3 & $0.2,0.7$ & & \\
\hline Smoking status & 355 & & & & & \\
\hline Yes & 94 & $19.1(18)$ & 1.0 & Reference & & \\
\hline No & 261 & $19.2(50)$ & 1.0 & $0.5,1.8$ & & \\
\hline
\end{tabular}

Abbreviations: $\mathrm{Cl}$, confidence interval; $\mathrm{CTS}$, carpal tunnel syndrome; $\mathrm{NE}$, not estimable; $\mathrm{OR}$, odds ratio.

*Estimated from multivariable logistic regression. Variables shown remained in best-fit model following backward selection starting from a model including all variables in the table; $n=245$ respondents with no missing values.

variables listed above. Female gender, BMI $>30$ and the presence of 1 or more of the selected comorbidities were independently associated with self-reported CTS (Table 2).
CTS symptoms in study population

Individuals self-reporting CTS were also more likely to indicate that they experience symptoms and difficulty with activities typically associated with diagnosed CTS than 


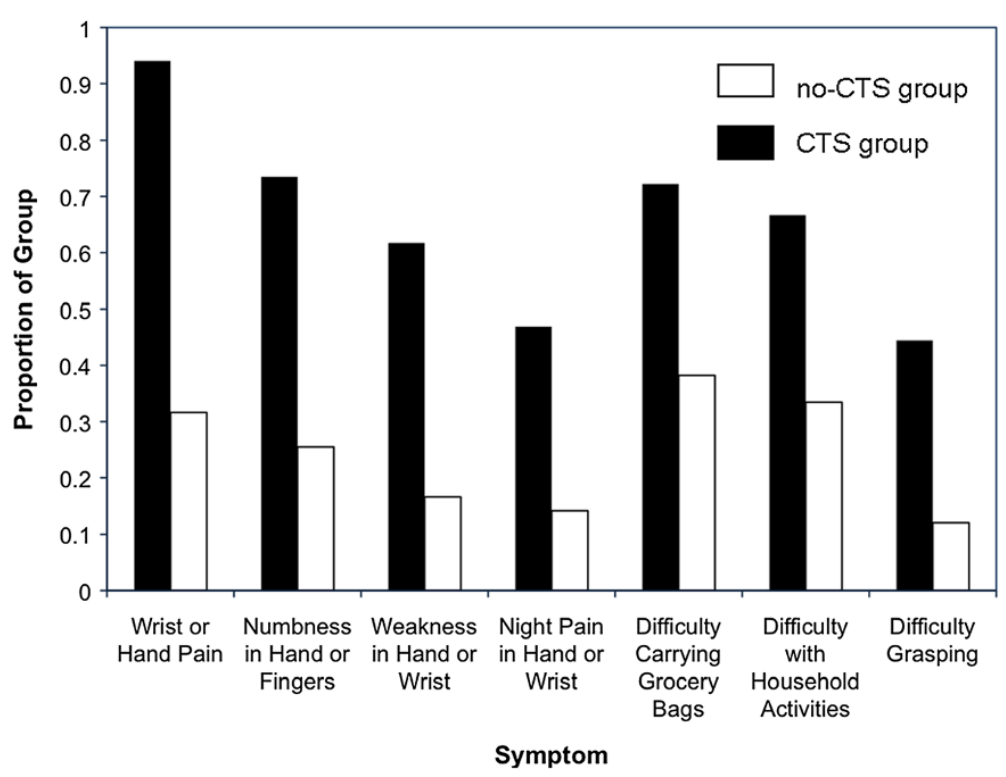

Figure 2 Common symptoms of CTS reported by survey respondents. Detailed Legend: Common symptoms of CTS reported by proportion of group self-reporting CTS (black bars) and by group not self-reporting CTS (white bars). Significant difference between groups for each symptom (Chi-Square Tests for Association: $P<0.05$, for each).

individuals who did not self-report CTS (Figure 2; $P<0.05$ for each, Chi-square Tests of Association). Among those who did not report CTS, symptoms and difficulties were not uncommon (12\%-38\%; Figure 2$)$. In contrast to the $4.5 \%(4 / 88)$ of individuals initially self-reporting CTS who indicated they were seeking treatment from a healthcare professional for their CTS, 68.4\% (54/79) of those reporting CTS at the end of the survey indicated that they were now interested in seeking medical treatment.

\section{Conclusion}

We report that the prevalence of self-reported CTS among office workers in Kuwait to be $18.7 \%$, which is higher than has been reported in other non Arabian Peninsula countries [3-6]. The CTS prevalence estimate in this study may differ from previous studies due to real differences among office workers in Kuwait or the diagnosis of CTS in Kuwait. The fact that the definition of self-reported CTS in this study did not require current symptoms also may have contributed to higher estimate of self-reported CTS prevalence. Only $2.8 \%$ of the entire sample reported CTS diagnosis from a health profession, which supports the finding that prevalence of CTS by self-report tends to be much higher as compared to clinical exam and nerve conduction testing $[5,13,14]$. It would be expected that the estimated prevalence of CTS would decrease if clinical diagnosis and/or nerve conduction testing were used to validate the estimate; however, the magnitude of that decrease in this setting cannot be predicted. Similar to other research we found selfreported CTS to be more common in women than men $[5,6]$, and that there is an association between self-reported
CTS and obesity and relevant comorbidities [10,15]. As in recent reviews, computer use could not be shown as a definitive risk factor for CTS [16-18]. This study is limited by the use of a self-report measure rather than a clinical assessment, and by the use of a questionnaire that was not formally validated. Additional results were presented to provide context for the self-report prevalence estimate, including the proportion of those with diagnosed CTS and the prevalence of individual symptoms, some of which are used to diagnose CTS in the clinical setting (nocturnal sensory symptoms, numbness in the median nerve distribution, aggravating and alleviating factors). Reassuringly, the symptoms and functional impairments experienced by those who self-reported CTS were consistent with the clinical profile of CTS.

To our knowledge, this study presents the first estimate of self-report CTS prevalence in Kuwait and the first to suggest that a substantial proportion of individuals who did not self-report CTS describe high frequency of CTS symptoms. Given the dearth of information of the prevalence of CTS in this region of the world, we feel that selfreport estimates of CTS can be taken in context as support for the need for further research into the prevalence of clinically diagnosed CTS and the possibility that CTS may be under-recognized in the general population in Kuwait. These findings, together with the documented high prevalence of factors associated with CTS in Kuwait [19-21] may signal that programs for the identification, prevention and intervention of musculoskeletal conditions such as CTS may have broad applicability across Kuwait. These data represent an important first step in recognizing what 
may be an emerging issue for occupational health across Kuwait.

\section{Additional file}

Additional file 1: Appendix A. Carpal tunnel syndrome study in office workers in Kuwait June 2008

\section{Abbreviations}

BMI: Body Mass Index; Cl: Confidence Interval; CTS: Carpal Tunnel Syndrome; NCV: Nerve Conduction Velocity; NE: Not Estimable; OR: Odds Ratio; WHO: World Health Organization.

\section{Competing interests}

The authors declare that they have no competing interests.

\section{Acknowledgements}

The authors would like to acknowledge the Lothan Youth Achievement Centre (LOYAC), and Ahmad Al-Halabi, Fatima Dashi, Fatima Ali, and Zained Al-Oraier for their important contributions in data collection. The authors also thank Andrea Ottensmeyer for her assistance in preparing the manuscript during this study.

\section{Author details}

${ }^{1}$ Fawzia Sultan Rehabilitation Institute, Kuwait. ${ }^{2}$ Doctor of Physical Therapy Division, Dept of Community and Family Medicine, Duke University, Box 104002, Durham NC 27708, USA. ${ }^{3}$ Department of Physical Therapy, University of Toronto, Toronto ON, Canada.

\section{Authors' contributions}

SR contributed to the overall study design, data analysis, and writing drafts of earlier versions of this article. BH contributed to the overall study design, and lead the data collection and data entry components of this study, along with contributing to writing drafts of this manuscript. EH contributed to the overall study design, contributed to data collection and data entry, and contributed to writing drafts of this manuscript. MDL contributed to the overall study design, data analysis, and initiated the writing of all drafts of this manuscript. All authors read and approved the final manuscript.

Received: 8 February 2012 Accepted: 13 June 2012

Published: 13 June 2012

\section{References}

1. Palmer KT, Harris EC, Coggon D: Carpal tunnel syndrome and its relation to occupation: A systematic literature review. Occup Med (Oxf) 2007, 57 (1):57-66.

2. Barcenilla A, March LM, Chen JS, Sambrook PN: Carpal tunnel syndrome and its relationship to occupation: A meta-analysis. Rheumatology 2012, 51(2):250-261.

3. Tanaka S, Wild DK, Seligman PJ, Behrens V, Cameron L, Putz-Anderson V: The US prevalence of self-reported carpal tunnel syndrome: 1988 national health interview survey data. Am J Public Health 1994, 84 (11):1846-1848.

4. Ferry S, Pritchard T, Keenan J, Croft P, Silman AJ: Estimating the prevalence of delayed median nerve conduction in the general population. $\mathrm{Br} J$ Rheumatol 1998, 37(6):630-635.

5. Atroshi I, Gummesson C, Johnsson R, Ornstein E, Ranstam J, Rosen I: Prevalence of carpal tunnel syndrome in a general population. JAMA 1999, 282(2):153-158.

6. Shiri R, Miranda H, Heliovaara M, Viikari-Juntura E: Physical work load factors and carpal tunnel syndrome: A population-based study. Occup Environ Med 2009, 66(6):368-373.

7. Maghsoudipour M, Moghimi S, Dehghaan F, Rahimpanah A: Association of occupational and non-occupational risk factors with the prevalence of work related carpal tunnel syndrome. J Occup Rehabil 2008, 18(2):152-156.

8. Jackson RT, al-Mousa Z, al-Raqua M, Prakash P, Muhanna A: Prevalence of coronary risk factors in healthy adult Kuwaitis. Int J Food Sci Nutr 2001, 52 (4):301-311.
9. Shah NM, Behbehani J, Shah MA: Prevalence and correlates of major chronic illnesses among older Kuwaiti nationals in two governorates. Med Princ Pract 2010, 19(2):105-112.

10. Werner RA: Evaluation of work-related carpal tunnel syndrome. J Occup Rehabil 2006, 16(2):207-222.

11. Nathan PA, Keniston RC, Lockwood RS, Meadows KD: Tobacco, caffeine, alcohol, and carpal tunnel syndrome in American industry. A crosssectional study of 1464 workers. J Occup Environ Med 1996, 38(3):290-298.

12. World Health Organization: BMI Classification. Available at: http://apps.who. int/bmi/index.jsp?introPage=intro_3.html. Accessed on July 6, 2011.

13. Homan MM, Franzblau A, Werner RA, Albers JW, Armstrong TJ, Bromberg MB: Agreement between symptom surveys, physical examination procedures and electrodiagnostic findings for the carpal tunnel syndrome. Scand J Work Environ Health 1999, 25(2):115-124.

14. Lenderink AF, Zoer I, van der Molen HF, Spreeuwers D, Frings-Dresen MHW, van Dijk FJH: Review on the validity of self report to assess work related diseases. Int Arch Occup Environ Health 2012, 85:229-251.

15. Atcheson SG, Ward JR, Lowe W: Concurrent medical disease in workrelated carpal tunnel syndrome. Arch Intern Med 1998, 158(14):1506-1512.

16. Thomsen JF, Gerr F, Atroshi I: Carpal tunnel syndrome and the use of computer mouse and keyboard: A systematic review. BMC Musculoskelet Disord 2008, 9:134

17. Van Rijn RM, Huisstede BM, Koes BW, Burdorf A: Associations between work-related factors and the carpal tunnel syndrome-a systematic review. Scand J Work Environ Health 2009, 35:19-36.

18. Andersen JH, Fallentin N, Thomsen JF, Mikkelsen S: Risk factors for neck and upper extremity disorders among computers users and the effect of interventions: an overview of systematic reviews. PLoS One 2011, 6(5): e19691.

19. Memon A, Moody PM, Sugathan TN, El-Gerges N, Al-Bustan M, Al-Shatti A, Al-Jazzaf H: Epidemiology of smoking among Kuwaiti adults: Prevalence, characteristics, and attitudes. Bull World Health Organ 2000, 78 (11):1306-1315.

20. Al-Awadhi AM, Olusi SO, Moussa M, Shehab D, Al-Zaid N, Al-Herz A, Al-Jarallah K: Musculoskeletal pain, disability and health-seeking behavior in adult Kuwaitis using a validated Arabic version of the WHO-ILAR COPCORD core questionnaire. Clin Exp Rheumatol 2004, 22(2):177-183.

21. Al-Orifan FH, Badr HE, Se'edah MAS, Khadadah KE, Al-Kordi B, Abass A: Obesity and cardiovascular risk factors in Kuwaiti adults. Kuwait Med J 2007, 39(2):162-166.

doi:10.1186/1756-0500-5-289

Cite this article as: Raman et al:: Prevalence and risk factors associated with self-reported carpal tunnel syndrome (CTS) among office workers in Kuwait. BMC Research Notes 2012 5:289.

\section{Submit your next manuscript to BioMed Central and take full advantage of:}

- Convenient online submission

- Thorough peer review

- No space constraints or color figure charges

- Immediate publication on acceptance

- Inclusion in PubMed, CAS, Scopus and Google Scholar

- Research which is freely available for redistribution 